\title{
Bovine leukemia virus long terminal repeat variability: identification of single nucleotide polymorphisms in regulatory sequences
}

\author{
Aneta Pluta ${ }^{* *}$, Marzena Rola-Łuszczak ${ }^{1}$ Renée N Douville ${ }^{2,3}$ and Jacek Kuźmak
}

\begin{abstract}
Background: Limited data are available on the incidence of variations in nucleotide sequences of long terminal repeat (LTR) regions of Bovine Leukemia Virus (BLV). Consequently, the possible impact of SNPs on BLV LTR function are poorly elucidated. Thus, a detailed and representative study of full-length LTR sequences obtained from sixty-four BLV isolates from different geographical regions of Poland, Moldova, Croatia, Ukraine and Russia were analyzed for their genetic variability.
\end{abstract}

Methods: Overlap extension PCR, sequencing and Bayesian phylogenetic reconstruction of LTR sequences were performed. These analyses were followed by detailed sequence comparison, estimation of genetic heterogeneity and identification of transcription factor binding site (TFBS) modifications.

Results: Phylogenetic analysis of curated LTR sequences and those available in the GenBank database reflected the acknowledged env gene classification of BLV into 10 genotypes, and further clustered analysed sequences into three genotypes - G4, G7 and G8. Additional molecular studies revealed the presence of 97 point mutations distributed at 89 positions throughout all 64 LTR sequences. The highest rate of variability was noted in U3 and U5 subregions. However, the variability in regulatory sequences $\left(V_{R}\right)$ was assessed as lower than the variability within non-regulatory sequences $\left(V_{N R}\right)$ for both, U3 and U5 subregions. In contrast, $V_{R}$ value for $R$ subregion, as well as for the total LTR, was higher than the $V_{N R}$ suggesting the existence of positive selection. Twelve unique SNPs for these LTR sequences localized in regulatory and non-regulatory elements were identified. The presence of different types of substitutions lead to the abrogation of present or to the creation of additional TFBS.

Conclusion: This study represents the largest study of LTR genetic variability of BLV field isolates from Eastern part of Europe. Phylogenetic analysis of LTRs supports the clustering BLV variants based on their geographic origin. The SNP screening showed variations modifying LTR regulatory sequences, as well as altering TFBS. These features warrant further exploration as they could be related to proviral load and distinctive regulation of BLV transcription and replication.

Keywords: Bovine leukemia virus, Long-terminal repeat (LTR), Virus variability, Transcription factors

\footnotetext{
* Correspondence: aneta.pluta@piwet.pulawy.pl

'Department of Biochemistry, National Veterinary Research Institute, Puławy,

Poland

Full list of author information is available at the end of the article
}

(c) The Author(s). 2018 Open Access This article is distributed under the terms of the Creative Commons Attribution 4.0 International License (http://creativecommons.org/licenses/by/4.0/), which permits unrestricted use, distribution, and reproduction in any medium, provided you give appropriate credit to the original author(s) and the source, provide a link to the Creative Commons license, and indicate if changes were made. The Creative Commons Public Domain Dedication waiver (http://creativecommons.org/publicdomain/zero/1.0/) applies to the data made available in this article, unless otherwise stated. 


\section{Background}

Bovine leukemia virus (BLV) is the etiological agent of enzootic bovine leucosis (EBL), a chronic, lymphoproliferative disease associated with persistent lymphocytosis and B-cell lymphomas. BLV, together with human T-cell leukemia viruses type 1 and 2 (HTLV-1, HTLV-2), belong to the genus Deltaretrovirus of the family Retroviridae. BLV virions contain a diploid RNA genome that is reverse transcribed into doublestranded DNA, which is ultimately integrated into the host genome in the form of a provirus. The BLV genome consists of gag, pol and env, structural genes and a region $\mathrm{X}$ which contains several open reading frames for Tax, Rex, R3 and G4 regulatory proteins [1]. The Tax protein is involved in activation of transcription of viral mRNA, while Rex protein regulates the synthesis of BLV structural proteins [2, 3].

Whole BLV genome is flanked at both $5^{\prime}$ and $3^{\prime}$ ends by long terminal repeat (LTR) sequences $[4,5]$. Each LTR is composed of three regions called U3, R and U5. U3 plays a crucial role in the induction of BLV transcription, since its contains the viral promoter and several regulatory elements critical for the modulation of promoter activity [6-9]. The major regulatory elements are three repeated 21-bp Tax-responsive elements (TRE) that include imperfectly conserved cyclic AMPresponsive elements (CRE) matching the consensus sequence $5^{\prime}$-TGACGTCA-3'. CRE sites are used by cellular transcription factors ATF-1 and ATF-2, as well as cyclic AMP response element binding (CREB) proteins [10]. The virus-encoded Tax transactivator increases the DNA binding activity of CREB/ATF proteins by interacting with their bZip domains, which positively regulates the activation of BLV transcription. Besides the CRE elements, each TRE sequence includes an E box as a target sequence for the AP4 transcription factor. Additionally, the U3 region contains several other response elements, such as: a nuclear factor- $\mathrm{kB}$ (NF-kB) binding site, which permit activation of transcription in presence of NF- $\mathrm{KB}$ p50 and p65 proteins, a glucocorticoid response element (GRE) conferring responsiveness to dexamethasone in the presence of the Tax, and PU.1/Spi-B binding sites for ETS transcription factor family proteins [7-9]. Other elements which were involved in regulation of virus transcription are located downstream of transcription initiation site in R-U5 regions and include an upstream stimulatory factor (USF) binding site, downstream activator sequence (DAS) and an interferon regulatory factor (IRF) binding site, respectively [11-13].

Several studies have demonstrated that sequence variations in retroviral LTRs may affect interactions with transcription factors, leading to altered expression of viral genes and ultimately virus replication. Indeed, it was shown that mutations in lentiviral LTRs caused distinct transcriptional activities of HIV-1 and small ruminant lentiviruses [14, 15]. Genetic diversity within LTRs was also associated with decreased pathobiology in lungs or increased neurovirulence in sheep infected with ovine lentivirus [16, 17]. A correlation was also found between mutations within the Tax-responsive element of human HTLV-1 and increased virus replication [18]. Together, this points to subtle differences in transcription factor biding sites potentially impacting the global regulation and clinical outcomes of retrovirus infection.

Analysis of BLV LTR sequences is limited to few studies; however, the most extensive nucleotide analysis focused on the env gene, with the identification of ten distinct genotypes thus far [19-21]. Significant variability within 5' LTR sequences were found in BLV isolates from North America, Costa Rica, Japan and Belgium, and grouped in 7 genetic groups. Notably, these LTR sequences were more conserved than non-regulatory regions [22]. Recently, phylogenetic analysis of $5^{\prime}$ LTR sequences of BLV isolates from Brazil showed that these sequences clustered into five well-defined groups, with accumulation of nucleotide variability in the R-U5 region [23]. LTR variability has been correlated with altered BLV virulence and pathogeny [24]. In addition, nucleotides polymorphisms found within the LTR region was associated with the emergence of two distinct infection profiles [25].

Sero-epidemiological surveys revealed that BLV infection is widely disseminated throughout the world, with a high prevalence in North and South America, as well as some Asiatic and Middle Eastern countries [26]. Poland has declared freedom from EBL in 2017; however, the infection is still present in East European countries like Ukraine, Moldova and Russia. A common economic zone with these countries still creates a potential for negative impact on the protection of the cattle populations and maintenance of BLV-free herd status in Poland. EBL risks in dairy herds must be considered given the development of trade with Eastern European countries.

In this study, full-length LTR sequences obtained from 64 BLV isolates from different geographical regions of Poland, Moldova, Croatia, Ukraine and Russia were analyzed for their genetic variability. We have found new SNPs modifying LTR regulatory sequences and provided further evidence for positive selection pressure in particular regions of the LTR.

\section{Methods}

\section{Sample collection}

Blood samples were collected from 64 cattle, serologically positive for BLV infection, as was diagnosed by different commercially available ELISA kits (IDEXX, 
blocking ELISA) or AGID (agar gel immunodiffusion) tests. The animals came from 47 herds, located in 19 geographically distinct regions in five countries: Poland, Moldova, Croatia, Ukraine and Russia. Available information about the isolates is summarized in Table 1 . Blood samples from Russia, Moldova and Ukraine were originally obtained from collaborating laboratories: Urals State Scientific Research Institute of Veterinary Medicine, Russia; Republican Center for Veterinary Diagnostic, Moldova and National Scientific Center Institute of Experimental and Clinical Veterinary Medicine, Ukraine and were sent to the National Veterinary Research Institute in Pulawy in the form of dry pellets of peripheral blood leukocytes (PBLs). DNA sample from two cattle from Croatia was kindly supplied by Dr. D. Balic (Veterinary Institute Vinkovci, Croatia). Forty-seven blood samples from Poland were selected by local diagnostic laboratories during EBL monitoring programme between 2013 and 2016.

\section{DNA isolation}

PBLs were isolated from $10 \mathrm{~mL}$ of blood by centrifugation at $1500 \mathrm{~g}$ for $25 \mathrm{~min}$. Erythrocytes were haemolysed by osmotic shock with $\mathrm{H}_{2} \mathrm{O}$ and $4.5 \% \mathrm{NaCl}$. Afterwards, the cells were washed twice with PBS, aliquoted $\left(5 \times 10^{6}\right.$ cells), and stored as pellet at $-80{ }^{\circ} \mathrm{C}$ until DNA extraction. Five archived samples collected in 2009 from BLV positive cows from Poland were stored as DNA samples at $-20{ }^{\circ} \mathrm{C}$ until further use. Genomic DNA was extracted using a DNeasy Blood \& Tissue Kit (Qiagen), following the manufacturer's instructions. For each sample, genomic DNA concentration was measured using a nanophotometer (IMPLEN) and the samples were stored at $-20{ }^{\circ} \mathrm{C}$ until examination.

\section{Overlap extension PCR}

To amplify the BLV LTR sequences, an overlap extension PCR technique was developed. The general principle of the overlap extension PCR is shown in Fig. 1. This technique includes initial amplification of two fragments: 979 and 571 bp long. A 979 bp fragment was amplified using the following primers: P7736, 5' - TCGA TACCCTCCTTGTGGACC-3'; P8693: 5'-TGTTTGCCG GTCTCTCCTGGCC-3'. The conditions of amplification were as follows: $500 \mathrm{ng}$ of template DNA, $1 \mathrm{x}$ KAPA Buffer, $0.2 \mathrm{mM} \mathrm{dNTP}, 0.4 \mu \mathrm{M}$ each primer, $2 \mathrm{mM} \mathrm{MgCl}_{2}$ and $0.5 \mathrm{U}$ of KAPA Taq Polymerase. The amplification was run in Biometra T-Personal Thermocycler under following conditions: initial denaturation $95{ }^{\circ} \mathrm{C} 5 \mathrm{~min}$, subsequent steps $95^{\circ} \mathrm{C} 30 \mathrm{~s}$, annealing $65^{\circ}$ $\mathrm{C} 45 \mathrm{~s}$, extension $72{ }^{\circ} \mathrm{C} 1 \mathrm{~min}, 38$ cycles total, final additional extension $72{ }^{\circ} \mathrm{C} 7 \mathrm{~min}$, hold at $4{ }^{\circ} \mathrm{C}$. The second fragment a $571 \mathrm{bp}$ long was amplified using the following set of primers: P1: 5'-TGTATGAAAGATCATGCCG
A-3'; P609: 5' - GACCCAAAATGCCGCCGAG-3', at the same conditions except the annealing condition at $52{ }^{\circ} \mathrm{C} 45 \mathrm{~s}$ and a 40 -cycle run for the amplified product.

Finally, both PCR fragments were used at equimolar proportions as template to generate final fragment $914 \mathrm{bp}$ long using the following set of primers: P7843: 5'-ATTC TACCCCTAGGCGAGCC-3' and P571: 5'-GTTA GGGTTCCGGGGTGATC-3' and the same content of reaction mixture. Thermal conditions were as follows: initial denaturation $95^{\circ} \mathrm{C} 5 \mathrm{~min}$, subsequent steps $95^{\circ} \mathrm{C} 35 \mathrm{~s}$, annealing $64{ }^{\circ} \mathrm{C} 50 \mathrm{~s}$, extension $72{ }^{\circ} \mathrm{C} 1 \mathrm{~min} 15 \mathrm{~s}, 38$ cycles total, final additional extension $72{ }^{\circ} \mathrm{C} 9 \mathrm{~min}$, hold at $4{ }^{\circ} \mathrm{C}$. The sequences of all primers were designed using Primer 3 web-based software, found at http://www.bioinformatics.nl/cgi-bin/primer3plus/primer3plus.cgi. For all amplifications, the PCR products were visualized by $1.5 \%$ agarose gel electrophoresis with Simply Safe (EURx) staining $(5 \mu \mathrm{l} / 100 \mathrm{ml})$ in $1 \mathrm{X}$ TAE buffer.

\section{Sequencing of full-length LTR}

The PCR products were purified using a NucleoSpin Extract II Kit (Marcherey Nagel GmbH \& Co) and subsequently, three independent PCR amplification products of each BLV isolate were sent to Genomed SA Company (Warsaw, Poland) for DNA sequencing in both directions, using a 3730xl DNA Analyzer (Applied Biosystems) and a Big Dye Terminator v3.1 Cycle Sequencing Kit. Raw sequence data were viewed and proofread in Geneious Pro version 5.5.9 (Biomatters Ltd) [27], the reads of each sample were aligned. A consensus sequence was determined for each BLV isolate. The data were deposited in the GenBank database under accession numbers included in Table 2.

\section{Sequence data analysis}

The sequences generated from 64 field isolates from Poland (52), Moldova (4), Russia (5), Croatia (2) and Ukraine (1) were aligned with 17 sequences of previously characterized BLV isolates from other geographical locations using ClustalW algorithm implemented in Geneious Pro 5.5.9 (Table 1). The multiple alignment was submitted to the Modeltest version 0.1 .10 for the best model selection according to the Akaike information criterion (AIC). As a result, the HKY85 substitution model was applied in Geneious Pro to infer a phylogenetic tree according to Bayesian method. Genetic distance analysis between newly obtained sequences and average nucleotide substitution per site were calculated using the Jukes-Cantor model in MEGA version 5.2.2. Statistical analyses were performed using STATISTICA version 10 (StatSoft, Dell Software, USA).

To detect selection on noncoding DNA we used similar approach to Hahn et al. and Zhao et al. [22, 28]. A standard indication of selective pressure is the ratio of 
Table 1 Identity and origin of the sequences analysed in the study

\begin{tabular}{|c|c|c|c|c|}
\hline GenBank accession no & Collection date & Geographic origin \& voivodeship & Genotype & Identity code \& source \\
\hline $\mathrm{MH} 423660$ & 2013 & Poland: Kuyavian-Pomeranian & $4-1 \|$ & 0221AGD_K-P, this work \\
\hline MH423661 & & Poland: Kuyavian-Pomeranian & $4-1 \|$ & 0222GD_K_P, this work \\
\hline MH407744 & & Poland: Silesian & $4-\|$ & 020B_S, this work \\
\hline MH423662 & & Poland: Lower Silesian & $8-1$ & 01390_L_S, this work \\
\hline MH423663 & & Poland: Lower Silesian & $8-1$ & 01350_L_S, this work \\
\hline $\mathrm{MH} 423664$ & & Poland: Lower Silesian & $8-1$ & 01330_L_S, this work \\
\hline MH423665 & & Poland: Lower Silesian & $8-1$ & 0132O_L_S, this work \\
\hline MH423666 & & Poland: Podlaskie & $8-1$ & 019WM_P, this work \\
\hline MH423667 & & Poland: Podlaskie & $7-1$ & 0184S_P, this work \\
\hline MH423668 & & Poland: Warmian-Masurian & $4-1$ & 030O_W-M, this work \\
\hline MH423669 & & Poland: Warmian-Masurian & $4-1 \mid I$ & 3208M_W-M, this work \\
\hline MH423670 & & Poland: Warmian-Masurian & $4-\mid I I$ & 3206M_W-M, this work \\
\hline MH423653 & 2014 & Poland: Warmian-Masurian & $8-1$ & 0405W_W-M, this work \\
\hline MH423654 & & Poland: Warmian-Masurian & $4-1$ & 4W_W-M, this work \\
\hline MH423655 & & Poland: Warmian-Masurian & $4-1$ & 0071B_W-M, this work \\
\hline $\mathrm{MH} 423656$ & & Poland: Warmian-Masurian & $4-1$ & 0072B_W-M, this work \\
\hline MH407735 & & Poland: Warmian-Masurian & $4-11$ & 0253G_W-M, this work \\
\hline MH407736 & & Poland: Warmian-Masurian & $4-11$ & 0252G_W-M, this work \\
\hline MH748226 & & Poland: Podlaskie & $7-11$ & 03511M_P, this work \\
\hline MH423657 & & Poland: Warmian-Masurian & $4-\|$ & 0242K_W-M, this work \\
\hline MH423658 & & Poland: Podlaskie & $7-1$ & 03513M_P, this work \\
\hline MH407742 & & Poland: Silesian & $4-\|$ & 0741M_S, this work \\
\hline MH407743 & & Poland: Silesian & $4-\|$ & 053K_S, this work \\
\hline MH423659 & & Poland: Lodz & $4-1 \mid I$ & 047P_Lodz, this work \\
\hline $\mathrm{MH} 423647$ & 2015 & Poland: Warmian-Masurian & $4-1$ & 0094B_W-M, this work \\
\hline MH423648 & & Poland: Warmian-Masurian & $4-1$ & 0101B_W-M, this work \\
\hline MH423649 & & Poland: Warmian-Masurian & $4-1$ & 0102B_W-M, this work \\
\hline MH423650 & & Poland: Warmian-Masurian & $4-1$ & 017B_W-M, this work \\
\hline MH423651 & & Poland: Podlaskie & $8-1$ & 0081Z_P, this work \\
\hline MH407740 & & Poland: Silesian & $4-\|$ & 0131Z_S, this work \\
\hline MH407741 & & Poland: Silesian & $4-\|$ & 026Z_S, this work \\
\hline MH423652 & & Poland: Lublin & $8-1$ & 011TL_L, this work \\
\hline MH407738 & 2016 & Poland: Podlaskie & $4-1$ & 035S_P, this work \\
\hline MH423633 & & Poland: Greater Poland & $4-1$ & 015P_G_P, this work \\
\hline MH423634 & & Poland: Podlaskie & $4-1$ & 0168BP_P, this work \\
\hline MH423635 & & Poland: Podlaskie & $4-1$ & 0167BP_P, this work \\
\hline MH423636 & & Poland: Podlaskie & $4-1$ & 0166BP_P, this work \\
\hline MH423637 & & Poland: Podlaskie & $4-1$ & 01610BP_P, this work \\
\hline $\mathrm{MH} 423638$ & & Poland: Warmian-Masurian & $7-1$ & 019W_W-M, this work \\
\hline MH423639 & & Poland: Warmian-Masurian & $8-1$ & 010W_W-M, this work \\
\hline MH423640 & & Poland: Warmian-Masurian & $4-1$ & 038W_W-M, this work \\
\hline MH423641 & & Poland: Warmian-Masurian & $4-\mid I I$ & 0371B_W-M, this work \\
\hline MH423642 & & Poland: Warmian-Masurian & $4-|| I$ & 0374B_W-M, this work \\
\hline $\mathrm{MH} 423643$ & & Poland: Warmian-Masurian & $4-1||$ & 0378B_W-M, this work \\
\hline
\end{tabular}


Table 1 Identity and origin of the sequences analysed in the study (Continued)

\begin{tabular}{|c|c|c|c|c|}
\hline GenBank accession no & Collection date & Geographic origin \& voivodeship & Genotype & Identity code \& source \\
\hline $\mathrm{MH} 423644$ & & Poland: Warmian-Masurian & $4-1$ & 009B_W-M, this work \\
\hline MH423645 & & Poland: Warmian-Masurian & $4-1$ & 006B_W-M, this work \\
\hline MH423646 & & Poland: Kuyavian-Pomeranian & $4-1$ & 014NN_K-P, this work \\
\hline MG407617 & 2012 & Moldova: Region Hincesti & $7-11$ & $13 \mathrm{MD}$, this work \\
\hline MG407616 & & Moldova: Region Hincesti & $7-11$ & $16 \mathrm{MD}$, this work \\
\hline MG407618 & & Moldova: Region Riscani & $7-11$ & $1 \mathrm{MD}$, this work \\
\hline MG407619 & & Moldova: Region Riscani & $4-\|||$ & $8 \mathrm{MD}$, this work \\
\hline MH423631 & 2009 & Croatia & $8-11$ & VRA_Cro, this work \\
\hline MH423630 & & Croatia & $8-11$ & ORA_Cro, this work \\
\hline MH423632 & & Ukraine: Rivnenska Oblast & $4-1 \|$ & 42UA_Ukr, this work \\
\hline MH423671 & & Russia: Kurgan area & $4-I V$ & 3K_Rus, this work \\
\hline MH423672 & & Russia: Chyelabinsk & $4-1 \|$ & 4Z_Rus, this work \\
\hline MH423673 & & Russia: Krasnodar Territory & $4-1 \|$ & 5.RU_Rus, this work \\
\hline MH423674 & & Russia: Tyumen & $4-I V$ & 6T_Rus, this work \\
\hline MH423675 & & Russia: Chyelabinsk & $4-1 \|$ & 8Ch_Rus, this work \\
\hline MH407739 & & Poland: West Pomeranian & $7-1$ & 146_W_P, this work \\
\hline MH407737 & & Poland: Opole & $4-11$ & 301_O, this work \\
\hline MH423676 & & Poland: Greater Poland & $4-1 \|$ & 58_G_P, this work \\
\hline MH423677 & & Poland: Greater Poland & 4 & 68_G_P, this work \\
\hline MH423678 & & Poland: Masovian & 4 & 297WS_M, this work \\
\hline AB934282.1 & 2014 & Japan & 1 & Mekata et al. (2014) ${ }^{b}$ \\
\hline EF600696.1 & 1985 & USA, subclone pBLV913 & 1 & Derse, 1985 [42] \\
\hline HE967301.1 & 2012 & Uruguay & 1 & Moratorio et al. (2012) \\
\hline LC164084.1 & 2016 & Japan & 1 & Murakami, 2016 [43] \\
\hline AF257515.1 & 2000 & Argentina & 2 & Dube, 2000 [44] \\
\hline LC080655.1 & 2007 & Paraguay & 2 & Polat, 2016 [19] \\
\hline LC080654.1 & 2008 & Peru & 2 & Polat, 2016 [19] \\
\hline LC080662.1 & 2008 & Bolivia & 9 & Polat, 2016 [19] \\
\hline LC080666.1 & 2008 & Bolivia & 9 & Polat, 2016 [19] \\
\hline DQ288214.1 & 2005 & Japan & 3 & Zhao, 2007 [22] \\
\hline DQ288182.1 & 2005 & USA & 3 & Zhao, 2007 [22] \\
\hline DQ288222.1 & 2005 & Costa-Rica & 5 & Zhao, 2007 [22] \\
\hline DQ288228.1 & 2005 & Costa-Rica & 5 & Zhao, 2007 [22] \\
\hline LC080657.1 & 2007 & Paraguay & 6 & Polat, 2016 [19] \\
\hline LC080658.1 & 2007 & Paraguay & 6 & Polat, 2016 [19] \\
\hline LC154848.1 & 2014 & Myanmar & 10 & Polat, 2017 [45] \\
\hline LC154849.1 & 2014 & Myanmar & 10 & Polat, 2017 [45] \\
\hline
\end{tabular}

${ }^{a}$ Moratorio et al. (2012) unpublished, direct submission to GenBank

${ }^{\mathrm{b}}$ Mekata et al. 2014, unpublished, presented and classified by Polat et al. 2017 [45]

$\mathrm{dN} / \mathrm{dS}$, where $\mathrm{dN} / \mathrm{dS} \sim 1$ signifies neutral evolution or a balance in evolutionary pressure on that sequence, $\mathrm{dN} / \mathrm{dS}$ $<1$ indicates negative or purifying selection and a ratio $>1$ indicates positive selection pressure $[29,30]$. By analogy, we measured the ratio of the substitutions per site in regulatory sites $\left(\mathrm{V}_{\mathrm{R}}\right)$ to non-regulatory sites $\left(\mathrm{V}_{\mathrm{NR}}\right)$ in LTR region, with the same interpretation of results. To compare variability (number of substitutions per nucleotide per strain) in $V_{R}$ versus $V_{N R}$ sequences of LTRs representing $64 \mathrm{BLV}$ isolates, the Friedman test was applied. The following regulatory elements of the LTR were analyzed: TRE1 (CRE1, E box 1), TRE2 (CRE2, E box 2), TRE3 


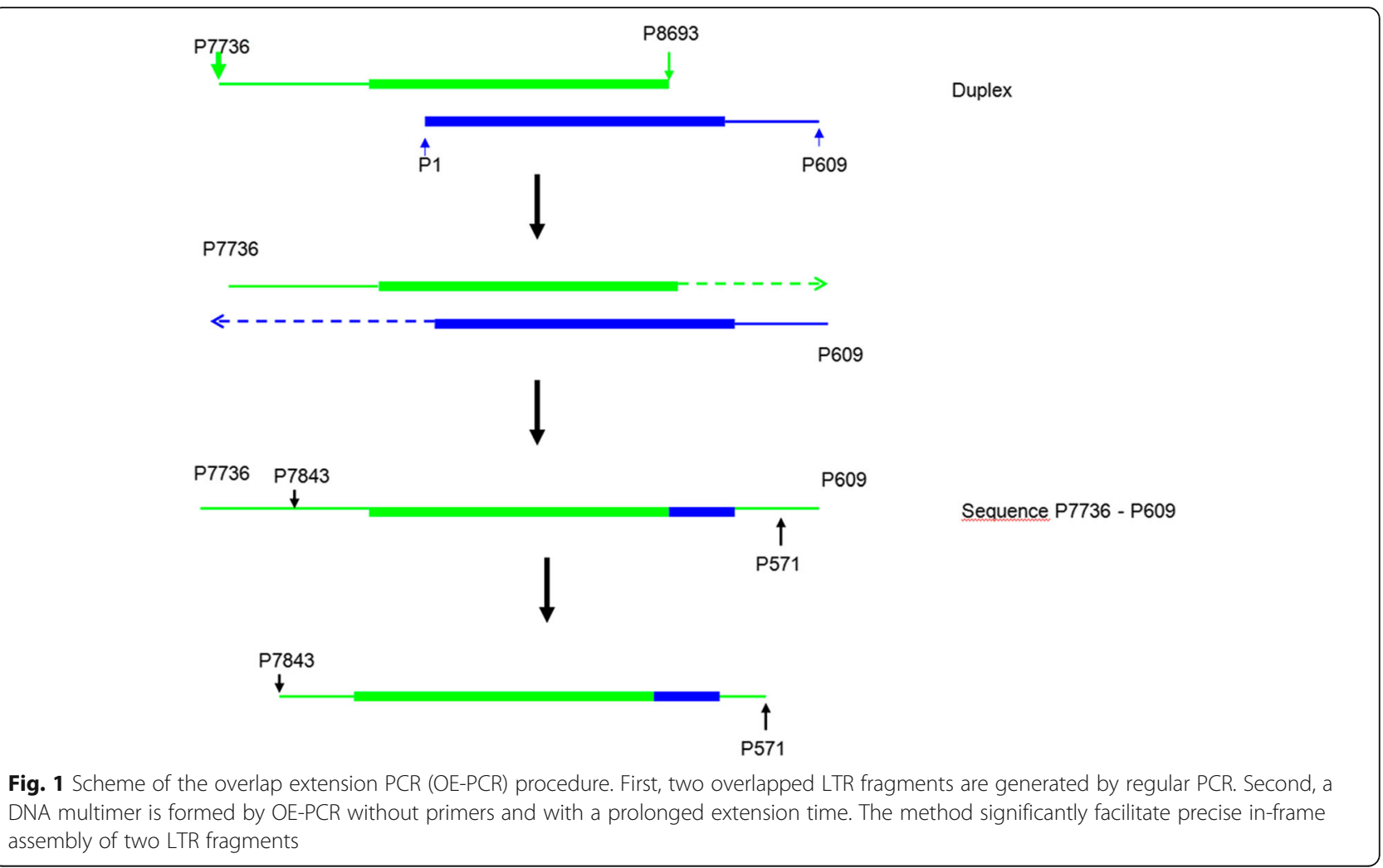

(CRE3, E box 3), PU.1/Spi-B, кB, GRE, TATA Box, PAS, CAP site, USF, DAS (BoxA, BoxB, BoxC), Poly(A) and IRF. The remaining sequences within the LTR were considered as non-regulatory sequences. The level of variability between particular subregions of the LTR (U3-R-U5) was assessed using Wilcoxon matched pair test.

In further study, the consensus sequence was calculated based on the multiple alignment and it was used to determined nucleotide variations within each LTR in respect to known BLV genotypes (G1-G10). To analyze the transcription factor binding site (TFBS) modifications related to specific mutations, the multiTF server was used (http://multitf.dcode.org).

\section{Results}

Analysis of the sequence variation within BLV LTRs

Table 2 shows average genetic distances estimated for the 64 sequences obtained in this study, as well as 17 sequences from other studies (insert reference here), representing named reference sequences from other

Table 2 Mean of nucleotide distances for BLV LTR isolates. Values of the mean of estimates of evolutionary divergence over sequence pairs between groups

\begin{tabular}{|c|c|c|c|c|c|c|c|c|c|c|c|}
\hline \multicolumn{2}{|c|}{ Origin/number } & \multirow[t]{2}{*}{1} & \multirow[t]{2}{*}{2} & \multirow[t]{2}{*}{3} & \multirow[t]{2}{*}{4} & \multirow[t]{2}{*}{5} & \multirow[t]{2}{*}{6} & \multirow[t]{2}{*}{7} & \multirow[t]{2}{*}{8} & \multirow[t]{2}{*}{9} & \multirow[t]{2}{*}{10} \\
\hline 1 & Poland $(n=52)$ & & & & & & & & & & \\
\hline 2 & Croatia $(n=2)$ & 0.017 & & & & & & & & & \\
\hline 3 & Ukraine $(n=1)$ & 0.012 & 0.017 & & & & & & & & \\
\hline 4 & Moldova $(n=4)$ & 0.024 & 0.029 & 0.021 & & & & & & & \\
\hline 5 & Russia $(n=5)$ & 0.015 & 0.019 & 0.008 & 0.022 & & & & & & \\
\hline 6 & Japan $(n=3)$ & 0.016 & 0.013 & 0.013 & 0.023 & 0.016 & & & & & \\
\hline 7 & Myanmar $(n=2)$ & 0.028 & 0.028 & 0.026 & 0.035 & 0.027 & 0.023 & & & & \\
\hline 8 & USA $(n=2)$ & 0.015 & 0.012 & 0.012 & 0.022 & 0.015 & 0.007 & 0.023 & & & \\
\hline 9 & South America $(n=8)$ & 0.022 & 0.021 & 0.019 & 0.028 & 0.022 & 0.016 & 0.027 & 0.014 & & \\
\hline 10 & Costa Rica $(n=2)$ & .0 .029 & 0.028 & 0.026 & 0.037 & 0.028 & 0.024 & 0.032 & 0.023 & 0.028 & \\
\hline
\end{tabular}

The number of base differences per site from averaging over all sequence pairs between groups is shown. The analysis involved 81 nucleotide sequences. All positions containing gaps and missing data were eliminated. There was a total of 526 positions analyzed in the final dataset. The number of isolates in each group $(\mathrm{n})$ is listed 
geographical locations. The level of divergence ranged between 0.012 to 0.037 , when the two populations of sequences were analyzed. Genetic distances calculated for the 64 sequences varied between 0.008 and 0.029 and were comparable to those noted for reference sequences.

To identify the extent of genetic variations within the 64 LTR sequences, a consensus sequence was constructed (Additional file 1). Sequence variations were found amongst all BLV isolates. We found $97(0.285 \%)$ point mutations distributed at 89 positions, along the 531 bp LTR amplicons of all 64 sequences. Among them, 46 were present in more than one isolate. The highest rate of variability was noted in U3 and U5 subregions $(0.173$ and 0.264 , respectively), while the variability found in $\mathrm{R}$ subregion was relatively low $(0.140)$. In fact, statistically significant differences were noted between the U5/R $(p$-value $=0.001155)$ and $\mathrm{U} 3 / \mathrm{R}(p$-value $=0.000002)$.

The most frequent changes were observed in regulatory elements of the U3 subregion and were characterized by substitution of G(-133)A/C in the TRE2 of seven sequences, substitution $\mathrm{T}(-65) \mathrm{C}$ in the GRE seen in 28 sequences, and substitution of $\mathrm{T}(-41) \mathrm{A}, \mathrm{T}(-37) \mathrm{A}$ and $\mathrm{T}(-36) \mathrm{C}$ in the TATA Box, noted in 4, 9 and 17 sequences, respectively.

The remaining variations were noted in DAS regulatory element of $\mathrm{R}$ subregion, and were characterized by substitution of $\mathrm{A}(+150) \mathrm{G}$ found in 8 sequences, $\mathrm{T}(+$ $161) \mathrm{C}$ found in 3 sequences, and substitution of $\mathrm{TC}(+$ 188/9)CT and $\mathrm{T}(+190) \mathrm{C}$ recognized in 11 sequences.

Despite the high variability within the U5 subregion, no accumulation of specific mutations within regulatory elements was noted. Additionally, the LTR sequence analysis revealed the presence of insertions and deletions in LTR. Four deletions at position $C(-72)$ del of GRE, $\mathrm{T}(-11)$ del of CAP site, $\mathrm{TC}(+188 / 9)$ del of BoxC and $\mathrm{A}(+320)$ del in non-regulatory site were observed. Two insertions at $T(+191)$ ins and $C(+192)$ ins were found in DAS and a non-regulatory site, respectively.

\section{Selection pressure in BLV LTR sequences}

A substantial number of SNPs found in regulatory sequences of LTR suggested the possibility of positive selective pressure on BLV LTRs. To examine this hypothesis, the variability in regulatory $\left(\mathrm{V}_{\mathrm{R}}\right)$ versus non-regulatory $\left(\mathrm{V}_{\mathrm{NR}}\right)$ sequences was calculated and compared using Wilcoxon matched pair test. The respective results were shown in Table 3. Variability in regulatory sequences $\left(V_{R}\right)$ was lower than the variability within non-regulatory sequences $\left(V_{N R}\right)$ for both, U3 and U5 subregions. $V_{R}$ versus $V_{N R}$ was lower than 1 showing a high probability of negative selection $(\mathrm{p}<$ 0.05 for $\mathrm{U} 3$ and $\mathrm{p}<0.0005$ for U5). Conversely, $\mathrm{V}_{\mathrm{R}}$ value for $R$ subregion, was higher than the $V_{N R}$ suggesting the existence of positive selection $(p<0.0001)$. For total LTR non-significant positive selection was predicted $(p<0.900)$.

\section{Phylogenetic analysis}

Based on the multiple sequence alignment of 64 sequences and 17 reference sequences, a phylogenetic tree was constructed using the Bayesian method. The topology, with high posterior probabilities, indicated that all sequences were clearly classified into ten distinct groups (Fig. 2). This topology fully matched the phylogenetic tree which was constructed on the basis of a $444 \mathrm{bp}$ fragment of the env gene, representing the same BLV isolates, with the presence of ten known BLV genotypes (G1-G10).

Analyzed sequences were segregated into three main groups, corresponding to the G4, G7 and G8 genotypes. Forty-five sequences representing Polish isolates and sequences from Moldova, Russia and Ukraine were clustered together within G4 genotype with a posterior probability of 0.62 . Further, they were clearly separated into distinct subgroups, designated as G4-I, G4-II, G4-III and G4-IV. G4-III was cosmopolitan group including sequences from Poland, Ukraine, Russia and Moldova, while the remaining G4 subgroups represented only sequences from Poland.

The genotype G8, with high posterior probability score 1.00 , grouped nine sequences from Poland and two sequences from Croatia, creating two separated subgroups G8-I and G8-II, respectively. All eight remaining sequences were found to create a G7 genotype with high posterior value 1.00. Five out them exclusively represented sequences from Poland forming a G7-I subgroup, while three sequences from Moldova were assigned to the G7-II subgroup.

Table 3 Evidence of selective pressure in regulatory sequences of U3, R, U5 regions and total BLV LTRs

\begin{tabular}{|c|c|c|c|c|c|c|c|c|}
\hline & \multicolumn{2}{|l|}{ U3 } & \multicolumn{2}{|l|}{ R } & \multicolumn{2}{|l|}{ U5 } & \multicolumn{2}{|l|}{ Total LTR } \\
\hline & Mean & Variance & Mean & Variance & Mean & Variance & Mean & Variance \\
\hline$V_{R}$ & 0.009141 & 0.000068 & 0.012219 & 0.000220 & 0.005188 & 0.000410 & 0.010031 & 0.000048 \\
\hline$V_{N R}$ & 0.013453 & 0.000167 & 0.00450 & 0.000031 & 0.017406 & 0.000270 & 0.009906 & 0.000054 \\
\hline$V_{R} N_{N R}$ & 0.679443 & & 2.715278 & & 0.298025 & & 1.012618 & \\
\hline$p$-value & $<0.05$ & & $<0.0001$ & & $<0.0005$ & & $<0.900$ & \\
\hline
\end{tabular}

$V_{R}$ Variability in regulatory sequences (regulatory elements), $V_{N R}$ Variability in non-regulatory sequences, $V_{R} V_{N R}$ The ratio was calculated to obtain evidence of selection; $<1$ for negative, $=1$ for neutral and $>1$ for positive selection. $V_{\mathrm{R}} / \mathrm{V}_{\mathrm{NR}}$ values representing positive selection was bolded 


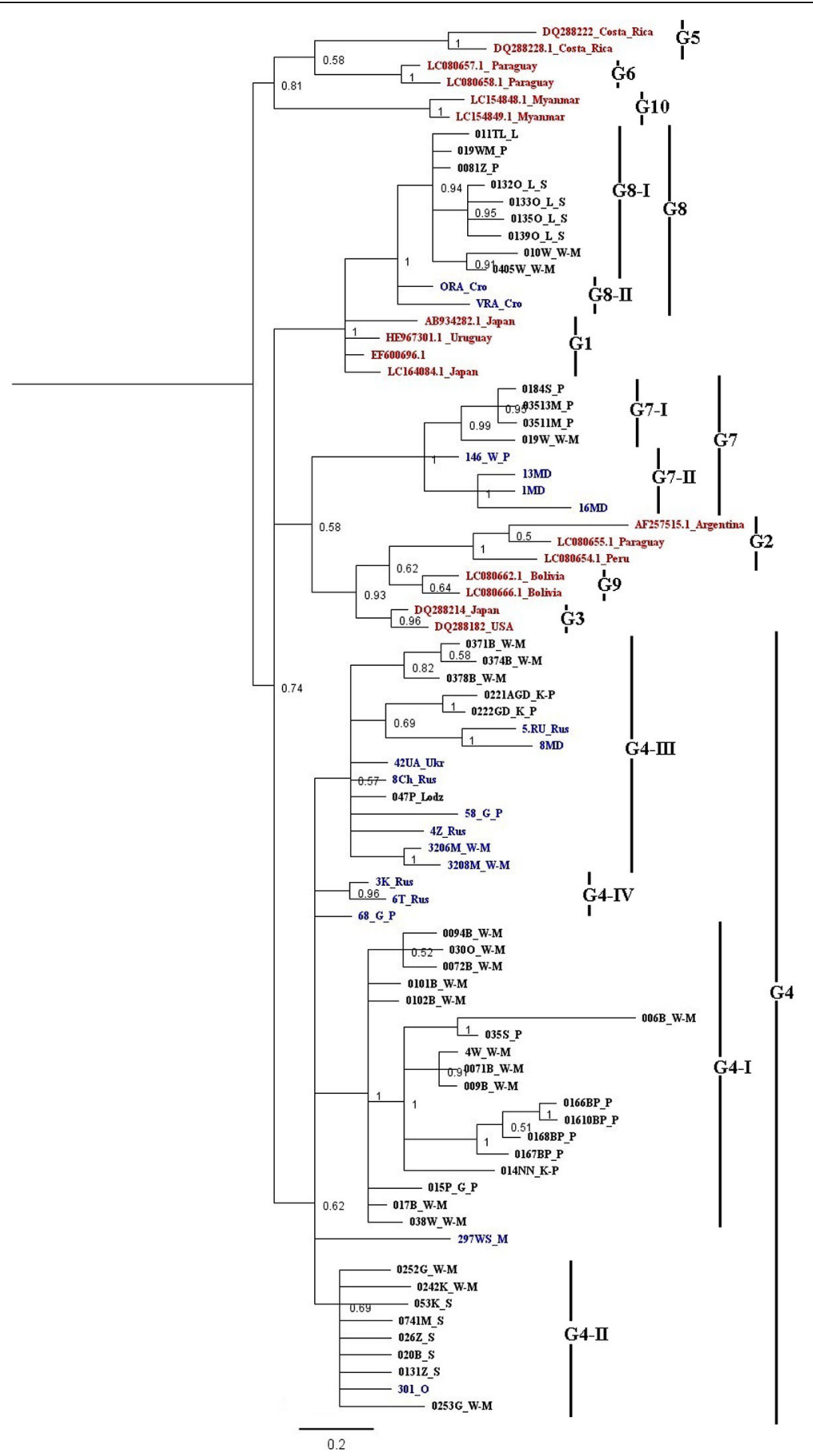

Fig. 2 Phylogenetic relationship of BLV genotypes and subtypes. The relationships between sequence data obtained in this study between 2009 and 2012 (indicated by blue color, $n=17$ ), selected from EBL monitoring programmes between 2013 and 2016 (indicated by black color, $n=47$ ) and additional reference sequences in GenBank (dark red color, $n=17$ ) were inferred by Bayesian analysis of LTR sequences, based on the HKY85 substitution model. Novel and known genotypes and/or subtypes found in this study are indicated at the right by vertical lines

\section{Selection pressure in genotypes and subtypes}

The variability in $V_{R}$ versus $V_{N R}$ sequences was further calculated to estimate any selection pressure on LTR regulatory elements in individual genotypes and subgroups detected in this study. The respective results were shown in Table 4. For most of the phylogenetic groups, the LTR sequences were under negative or neutral selection. However, positive selection was estimated in the $\mathrm{R}$ region of the LTR sequences representing genotype G4 $(p<0.006039)$ and G8 $(p<0.000002)$. In 
Table 4 Evidence of selection on BLV total LTR in each genotype and subtype

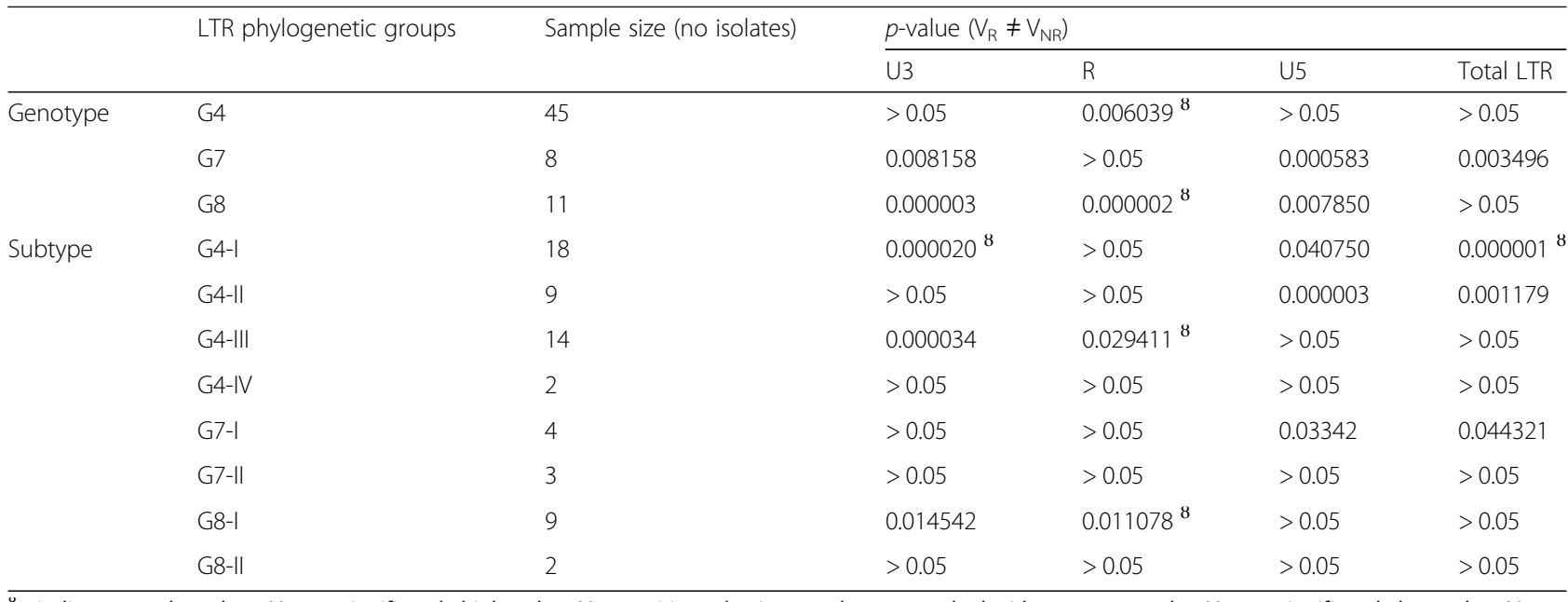

${ }^{8}$ - indicates $p$-value where $V_{R}$ was significantly higher than $V_{N R}$, positive selection; $p$-value not marked with an ou mean that $V_{R}$ was significantly lower than $V_{N R}$, negative selection; $p$-value $>0.05$ mean not significant difference between $V_{N R}$ and $V_{R}$; the 68_G_P, 146_W_P and 297WS_M sequences were not classified to the subtypes giving 61 sequences to the subtype analysis

particular, it was noted for the G4-III $(p<0.029411)$ cosmopolitan subgroup including Polish, Ukrainian, Moldavian and Russian sequences, as well as for G8-I $(p<0.011078)$ subgroup of Polish sequences. Positive selection was also detected in the U3 subregion $(p<$ $0.000020)$ and total LTR $(p<0.000001)$ of G4-I subgroup which included Polish sequences.

\section{Genotype-specific variability}

Based on the analysis of the multiple sequence alignment of 64 and 102 BLV LTR sequences collected in GenBank database (Additional file 2) it was possible to identify 15 unique SNPs for each of known genotype (G1-G10) and 6 subgroup-specific SNPs, which are presented in Table 5. Overall, 21 genotype and subgroupspecific SNPs at 19 positions were found. Nine out of 21 SNPs identified were located in TRE1, TRE2, GRE/ TRE3, TATA and DAS regulatory elements of the LTR. The remaining 12 were equally distributed among the non-regulatory sequences of the U3, R and U5 subregions.

Here we report that genotype/subgroup-specific variations appeared to be geographically stratified throughout locations of the donor cattle. Some SNPs were found exclusively in isolates from certain geographic areas: e.g. $\mathrm{T}(-41) \mathrm{A}$ and $\mathrm{T}(-36) \mathrm{C}$ in only Polish isolates; $\mathrm{G}(-133) \mathrm{C}, \mathrm{T}(+161) \mathrm{C}$ for only Moldovan isolates; $C(+162) \mathrm{T}$ for Russian isolates), while some were found in isolates from multiple areas (e.g G(170)A and $\mathrm{T}(-65) \mathrm{C}$ for Polish and Croatian isolates; A(- 203)G, G(- 202)A, A(+ 150)G for Polish and Moldavian isolates; $\mathrm{T}(+11) \mathrm{C}$ for Polish, Ukrainian, Moldavian and Russian isolates.

The detection of SNPs in regulatory elements suggested that there may be differential BLV expression in host infected with particular genotypes and/or subgroups. Five out of 9 SNPs identified in regulatory elements corresponded with G4, G7 and G8 genotypes. Another six out of 12 SNPs typical for these genotypes were identified in non-regulatory binding sites of the LTR.

To analyze transcription factor binding site (TFBS) modifications related to genotype and subgroup-specific SNPs for G4, G7 and G8 genotypes we used multiTF software. The data were evaluated for potential cellular transcription factors binding sites using an in silico analysis, in conjunction with SNPs that possibly abrogated existing TFBS or created a new TFBS (Table 6).

Five SNPs, identified in TREx2, GRE/TREx3, TATA Box, and DAS were contained XBP-3, GATA-1, CIIIB1, TMF, Pit-1a, TFIID, Sp1 and PR binding predicted sites as determined by in silico analysis. Variations disrupted putative sites for XBP-3, GATA-1, CIIIB1 and TMF, as well as possibly created new CREM-tau2, AP-1, GATA1, NF-E2, RAR-gamma2 binding sites.

Six other SNPs that were not identified in common regulatory binding motifs were present in TFIID, GATA1, Pit-1a, Sp1, TBP, AFP1 and PR binding putative sites determined by in silico analysis. Variations disrupted the predicted sites for TFIID, GATA-1, TBP and AFP1, and may have created new AP-1, PR, ACF binding putative sites. Future studies are required to assess the functional capacity of BLV promoters from distinct genotypes with divergent TF binding sites.

\section{Discussion}

In this study we determined the nucleotide sequences for LTRs of BLV proviruses isolated from naturally-infected cattle from Poland, Moldova, Ukraine, Russia and 
Table 5 Unique LTR nucleotide differences which permit genotype/subtype classification

\begin{tabular}{|c|c|c|c|c|c|c|c|c|c|c|c|c|c|c|c|c|c|c|c|c|c|c|c|c|}
\hline \multirow{4}{*}{$\begin{array}{l}\text { Genotype/ } \\
\text { subtype }\end{array}$} & \multicolumn{24}{|c|}{ LTR } \\
\hline & \multicolumn{11}{|c|}{ U3 } & \multicolumn{8}{|l|}{$R$} & \multicolumn{5}{|l|}{ U5 } \\
\hline & & & & & & 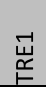 & 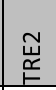 & \begin{tabular}{|l}
$\frac{m}{p}$ \\
$\frac{\dot{\varphi}}{z}$
\end{tabular} & 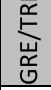 & $\underset{E}{\mathbb{E}}$ & & & & & & & 䀦 & 行 & 䀦 & & & & & \\
\hline & $\begin{array}{l}- \\
2 \\
0 \\
3\end{array}$ & $\begin{array}{l}- \\
2 \\
0 \\
2\end{array}$ & $\begin{array}{l}- \\
1 \\
7 \\
0\end{array}$ & $\begin{array}{l}- \\
1 \\
6 \\
9\end{array}$ & $\begin{array}{l}- \\
1 \\
6 \\
8\end{array}$ & $\begin{array}{l}- \\
1 \\
5 \\
6\end{array}$ & $\begin{array}{l} \\
1 \\
3 \\
3\end{array}$ & $\begin{array}{l}- \\
9 \\
5\end{array}$ & \begin{tabular}{|l}
- \\
6 \\
5
\end{tabular} & $\begin{array}{l}- \\
4 \\
1\end{array}$ & $\begin{array}{l}- \\
3 \\
6\end{array}$ & $\begin{array}{l}+ \\
1 \\
1\end{array}$ & $\begin{array}{l}+ \\
2 \\
5\end{array}$ & $\begin{array}{l}+ \\
5 \\
0\end{array}$ & $\begin{array}{l}+ \\
1 \\
3 \\
1\end{array}$ & $\begin{array}{l}+ \\
1 \\
5 \\
0\end{array}$ & $\begin{array}{l}+ \\
1 \\
6 \\
1\end{array}$ & $\begin{array}{l}++ \\
1 \\
6 \\
2\end{array}$ & \begin{tabular}{|l}
+ \\
1 \\
6 \\
3
\end{tabular} & $\begin{array}{l}+ \\
2 \\
3 \\
7\end{array}$ & $\begin{array}{l}+ \\
2 \\
4 \\
2\end{array}$ & $\begin{array}{l}+ \\
2 \\
6 \\
9\end{array}$ & $\begin{array}{l}+ \\
2 \\
7 \\
7\end{array}$ & $\begin{array}{l}+ \\
2 \\
8 \\
1\end{array}$ \\
\hline Consensus & A & G & G & $T$ & A & G & $G$ & A & $T$ & $T$ & $T$ & $T$ & C & C & $T$ & A & $T$ & C & $T$ & $G$ & $T$ & G & C & c \\
\hline $\mathrm{G1}$ & . & . & . & . & $\begin{array}{l}\text { A/ } \\
G\end{array}$ & . & . & . & . & . & . & . & . & . & . & . & . & . & . & . & . & . & . & . \\
\hline $\mathrm{G} 2$ & . & . & . & . &. & $\underline{A}$ & . & . & . & . & . & . & . & $\mathrm{T} / \mathrm{C}$ & . & . & . & 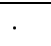 & $\underline{G}$ & . & $\underline{c}$ & . & . & . \\
\hline G3 & . & . & . & . & . & . & . & $\begin{array}{l}\mathrm{G} / \\
\mathrm{A}\end{array}$ & . & . & . & . & $I$ & . & . & . & . & . & . & . & . & . & . & . \\
\hline G4-I & 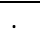 & . & . & $\mathrm{T} / \mathrm{C}$ & . & . & . &. & C &. & $C$ & $\underline{C}$ & . & . & . & . & . & . & . & . & & . & . & . \\
\hline G4-II & & . & . & . & . & & . & . & . &. & & $\underline{c}$ & . & . &. & . & . & &. & . & & . & . & . \\
\hline G4-III & . & . & . & . & . & . & \begin{tabular}{|l|}
$G /$ \\
$A$ \\
\end{tabular} & . & . &. & . & $\underline{c}$ & . & . & . & . & . & . & . & . & & . & . & . \\
\hline G4-IV & . & . & . & . & . & . &. & . & . & . & . & $\underline{c}$ & . & . & . & . & . & $T$ & . & . & & . & . & . \\
\hline G5 & . & . & . & . & . & . & . & . & . & . & . & . & . & . & $\frac{\mathrm{G} /}{\mathrm{A}}$ & . & . & & . & $\underline{A}$ & ${ }^{\circ}$ & . & . & . \\
\hline G6 & . & . & . & C & . & . & . & . & . & . & . & . & . & . &. & . & . & &. & . & . & . & . & . \\
\hline G7-I & $\underline{G}$ & $\underline{A}$ & . & . & . & & . & . & . & $A$ & &. & . & . & . & $\underline{G}$ & . & & . & . & & $\begin{array}{l}\text { A/ } \\
\text { G } \\
\end{array}$ & . & . \\
\hline G7-II & $\underline{\mathrm{G}}$ & $\underline{A}$ & . & . & . & 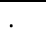 & C & . & . & . & . & . & . & . & . & $\underline{\mathrm{G}}$ & C & & . & . & . & $\cdot$ & . & . \\
\hline G8-I & . & . & $\underline{A}$ & . & . & 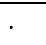 & . & . & $\underline{c}$ &. & . & . & . & . & . & . & . & & . & . & & . & . & . \\
\hline G8-II & . & . & $\underline{A}$ & . & . & . & . & . & $\underline{c}$ & . & . & . & . & . & . & . & . & . & . & . & & . & . & . \\
\hline G9 & & . & . & . & . & & . & . & . & . & . & . & . & . & . & . & . & & $\underline{c}$ & . & & . & . & . \\
\hline G10 & & . & . & . & G & & . & . & . & . & . & . & . & . & . & . & . & & . & . & & . & $I$ & $I$ \\
\hline
\end{tabular}

'Genotype/subtype' column include pattern of the nucleotide sequence for each genotype and subtype, G1-G10 as well as G4-I, G4-II, G4-III, G4-IV, G7-I, G7-II, G8-I and G8-II, respectively. Nucleotides are represented by single letters and numbered from the beginning of $5^{\prime}$ to $3^{\prime}$ end of LTR. Blue squares represent unique SNPs for G4, G7 and G8 genotypes and/or subtypes. Underlined nucleotides represent specific SNPs for genotypes G2-G10

Croatia. The 64 sequences analyzed proved to be $96.3-$ 98.2\% identical to the other BLV sequences isolated from cattle living in Japan, Myanmar, North, Central and South America. This data revealed that the genetic distances between BLV LTR sequences were very low among infected cattle and were comparable to that observed for coding sequences within the BLV genome. It was further shown that the homology of the env gene was $94.5-97.7 \%$ amongst BLV isolates representative of the ten genotypes.

Comparison the 64 LTR sequences with the previously described sequences from American and Asian countries reveals numerous SNPs which conferred differences throughout most of the length of the LTR. We propose that some of these differences may account for noted variability in viral transcription and replication. Expression of BLV is dependent on three imperfect $21 \mathrm{bp}$ repeats (TRE), which are critical elements for both basal expression and for transactivation by the virally-encoded Tax protein. These TRE motifs contain imperfectly conserved cyclic AMP-responsive elements (CRE), specifically AGACGTCA, TGACGGCA, and TGACCTCA sites, that repress transcriptional activation by cellular CREB/ ATF factors. This strategy avoids TRE site recognition during a host immune response [10]. We noted TRE variations which were located outside, $G(-133) A / C$, $\mathrm{T}(-65) \mathrm{C}$, and within the corresponding CRE octanucleotide, $\mathrm{C}(-53) \mathrm{A}$, which created an imperfect CRE (TGACCTCA). Besides, each TRE contains an E-box sequence (CAGCTG, CAGCTG and CACCTG) which overlaps the CRE motif. E boxes are can exert a negative cooperative effect on the activity of the BLV promoter through the CREs, most likely by sterically inhibiting the binding of CREB/ATF to these sites [31]. We found E 
Table 6 Potential binding sites for the cellular transcription factors that could be implicated in LTR activity. The analyzed mutation position relate to genotype and/or subtype specific SNPs for G4, G7 and G8 genotypes

\begin{tabular}{|c|c|c|c|c|c|c|}
\hline Mutation position & Change & $\begin{array}{l}\text { Previously described } \\
\text { regulatory elements }\end{array}$ & TFBS by multiTF & TFBS change & & $\begin{array}{l}\text { Genotype/ } \\
\text { subtype }\end{array}$ \\
\hline & & & & Creation & Abrogation & \\
\hline-203 & $A \rightarrow G$ & None & TFIID, GATA-1, Pit-1a & AP-1 & TFIID, GATA-1 & G7-I, II \\
\hline-202 & $G \rightarrow A$ & None & TFIID, GATA-1, Pit-1a & AP-1 & TFIID, GATA-1 & G7-I, II \\
\hline-170 & $\mathrm{G} \rightarrow \mathrm{A}$ & None & Sp1 & PR & - & G8-I, II \\
\hline-133 & $\mathrm{G} \rightarrow \mathrm{C}$ & TREX2 & XBP-3, GATA-1 & CREM-tau2, AP-1 & XBP-3, GATA-1 & G7-II \\
\hline-65 & $\mathrm{~T} \rightarrow \mathrm{C}$ & GRE/TREX3 & $\mathrm{ClIB} 1$ & GATA-1 & $\mathrm{ClIB} 1$ & G4-I, G8-I, II \\
\hline-41 & $\mathrm{~T} \rightarrow \mathrm{A}$ & TATA Box & $\begin{array}{l}\text { GATA-1, TMF, Pit-1a, } \\
\text { TFIID, Sp1, PR }\end{array}$ & NF-E2, RAR-gamma2 & GATA-1, TMF & G7-I \\
\hline-36 & $\mathrm{~T} \rightarrow \mathrm{C}$ & None & $\begin{array}{l}\text { TBP, AFP1, Pit-1a, } \\
\text { GATA-1, TFIID }\end{array}$ & $\mathrm{AP}-1, \mathrm{ACF}$ & TBP, AFP1 & G4-I \\
\hline+11 & $\mathrm{~T} \rightarrow \mathrm{C}$ & None & Sp1, PR & AP-1 & - & G4-I, II, III, IV \\
\hline+150 & $A \rightarrow G$ & None & GATA-1 & - & - & G7-I, II \\
\hline+161 & $\mathrm{~T} \rightarrow \mathrm{C}$ & DAS & PR & - & - & G7-II \\
\hline+162 & $\mathrm{C} \rightarrow \mathrm{T}$ & DAS & PR & Tf-LF1 & - & G4-IV \\
\hline
\end{tabular}

TFIID Transcription factor II D, GATA-1 Erythroid transcription factor, Pit-1a Growth hormone factor 1, AP-1 Activator protein 1, Sp1 Specificity protein 1, PR Progesterone, XBP-3 X-box binding protein 1, CREM-tau2 Transcription factor cAMP-response element modulator protein, CIIIB1 Nuclear factor, TMF TATA element modulatory factor, NFE2 TF interacting with CREB-binding protein, RAR-gamma2 Retinoic acid receptor gamma, control peptide, TBP TATA-binding protein, AFP1 Hepatoma nuclear factor that binds to the alpha-fetoprotein enhancer and promoter, ACF ATP-dependent chromatin-assembly factor, Tf-LF1 Liver-specific transcription factor

box variations, $\mathrm{T}(-147) \mathrm{C}, \mathrm{C}(-123) \mathrm{G}, \mathrm{C}(-48) \mathrm{T}$ and $\mathrm{T}(-$ $47) \mathrm{C}$, which may be involved in potentiating the basal activation of LTR-directed gene expression by CREB/ ATF family proteins. Other variations observed include $\mathrm{T}(-41) \mathrm{A}, \mathrm{T}(-37) \mathrm{A}$ and $\mathrm{T}(-36) \mathrm{C}$ substitution in TATA Box, which is a core promoter element that binds the cellular factor TATA-binding protein (TBP). TBP binds other cellular factors, as well as RNA polymerase II, to initiate transcription from the DNA template. The site-directed mutants TA(- 41 to -40$)$ AT and TT(- 37 to -38 )TTT of the TATA Box were shown to have significantly stronger responsiveness to Tax protein in comparison to the wild type LTR [32].

The numerous DAS variations, located downstream to the transcription initiation site, $\mathrm{C}(+134) \mathrm{T}$ and $\mathrm{A}(+$ $150) \mathrm{G}$ in BoxA, C(+166)T in BoxB, TC $(+188 / 9) \mathrm{CT}$ and $\mathrm{T}(+190) \mathrm{C}$ in BoxC and mutations outside of the boxes in DAS $\mathrm{G}(+156) \mathrm{A}, \mathrm{T}(+161) \mathrm{C} ; \mathrm{C}(+162) \mathrm{T} ; \mathrm{A}(+180) \mathrm{G}$, $\mathrm{T}(+182) \mathrm{C}, \mathrm{C}(+183) \mathrm{T}$ and $\mathrm{T}(+184) \mathrm{C}$ observed in this study might also introduce discrepancies in promoter activity. Specifically, these were included in three conserved boxes, which were found to be identical with HTLV-1 DRE 1, that is essential for up regulation of the HTLV-1 promoter [12, 33]. Kashanchi et al. revealed that the $45 \mathrm{nt}$ sequence DRE 1, located at the boundary of the R/U5 region of the LTR, is required for basal HTLV-1 transcription and plays an important role in the initiation and maintenance of virus replication [33]. There were also observed $\mathrm{T}(+256) \mathrm{C}, \mathrm{T}(+259) \mathrm{C} / \mathrm{G}$ and $\mathrm{C}(+264) \mathrm{T}$ changes in IRF binding site of the U5 region, which may also play role in initiation of virus replication [13].

Despite the overall differences described above, the sequences of several regulatory elements of the LTR were conserved. These included the TRE1, CRE2, NF-kB-like motif and PU.1/Spi-B binding site of U3. Another interesting feature of BLV LTRs is the presence of a conserved kappa B $(\mathrm{kB})$ site. Constitutive expression of NF- $\kappa \mathrm{B}$ in B cells can induce low level of transcription during BLV infection, which can be up-regulated following immunological activation and thus initiate a positive feedback loop involving the Tax protein [13]. Two SNPs, $\mathrm{T}(-104) \mathrm{C}$ and $\mathrm{T}(-84) \mathrm{C}$, were located within $\mathrm{kB}$ site and PU.1/Spi-B binding site, respectively. Notably, Xiao et al. revealed that $\mathrm{TC}(-83$ to -84$) \mathrm{CT}$ substitution in the PU.1/Spi-B binding site increased BLV promoter function fivefold [32].

In our work, we investigated possible natural selection over the entire BLV LTR sequence, as well as particular regions of the LTR (U3, R and U5), from 64 new BLV isolates and found evidence of negative selection for most of the regulatory elements. These results are consistent with the observations of Zhao et al., who showed significantly higher variability of non-regulatory than regulatory sequences in LTRs based on the analysis of 52 BLV isolates from USA, Japan and Costa Rica [22]. Nevertheless, in contrast to their findings of no evidence for positive selection for all LTR regions, we found evidence that regulatory sequences within $\mathrm{R}$ region were under positive selection, specifically the CAP site, USF, 
DAS: BoxA, BoxB, BoxC and Poly (A) sites. The essential difference in selection between these studies could be dictated by including the DAS element in this study, in contrast to Zhao and coworkers, who excluded it from their analysis. DAS is a 64 bp long sequence present at the $3^{\prime}$ end of the $\mathrm{R}$ region, which contributes to the enhancement of viral gene expression [12]. Interestingly, BLV DAS region harbors both progesterone and glucocorticoid binding sites, indicating a putative role in RNA synthesis. Asin et al. demonstrated that in HIV-1-infected cells, progesterone and estradiol regulate HIV-1 replication most likely by directly altering HIV-1 transcriptional activation and in the absence of the viral regulatory protein Tat [34]. Our analysis revealed that, unlike viral essential cis-acting promoter control sequences contained within U3 region (TRE1, CRE2, $\mathrm{KB}$ and PU_Box), R region can undergo continuous substitutions due to host selection pressure. This sequence variation of target transcription factor binding sites in $\mathrm{R}$ region may reduce the binding sites recognition and potentially be detrimental to the efficacy of transcription factors on the BLV LTR and/or hormone responsiveness. Since glucocorticoid (GR) and progesterone (PR) receptors are known to drive the activity of the HIV-1 and select endogenous retroviruses, we believe they may likely also modulate the activity of BLV 5' LTR [8, 34, 35].

Another finding emerging from the in silico analysis is the possibility that many additional cellular transcription factors could contribute to the regulation of BLV transcription. We found that genotype and subgroup-specific SNPs can lead to creation or abrogation several transcription factors in the LTR. The putative binding sites for transcription factors, unique for particular genotypes/subgroups, were observed notably for AP-1, PR, CREM-tau2, NF-E2, RAR-gamma2, GATA-1 and ACF. We postulate that these observed variations can lead to genotype/subtype- specific differences in viral gene expression.

In support of this concept, Jeeninga et al. revealed that the change from $\mathrm{kB}$ to GABP binding site in the LTR of HIV-1 subtype E did not lead to loss of promoter function; instead, a gain of GABP binding to this mutated $\mathrm{kB}$ binding site enhanced Tat-mediated gene expression and improved virus replication in select cell lines [36]. We found that the SNP G(-133)C, specific for G7-II, located in TREx 2 regulatory element, was found to introduce CREM-tau2 and AP-1 potentially leading to abrogation of the XBP-3 and GATA-1 binding putative sites. Interestingly, CREM isoforms are transcription factors belonging to the CREB/CREM/ATF family, which are known to cooperate with activator protein 1 (AP-1), were upregulated by Tax protein [37]. AP-1 transcription factor family include FOS, JUN, MAF, and ATF proteins, which are significantly upregulated in the presence of Tax $[37,38]$. This AP-1 can form different AP-1 dimers, which control transcriptional activation or suppression of many genes.

The SNP T(-41)A in the TATA Box, typical for the G7-I subtype, harbors a shift from an GATA-1/TMF to NF-E2/RAR-gamma2 binding putative sites. Interestingly, transcription factor NF-E2 is known to bind with a specific DNA sequence in order to modulate transcription by RNA polymerase II. These newly determined, in silico predicted TFBS can be useful for further experiments directed at defining the physical interactions between viral and host regulatory proteins, and may help define the biochemical processes of basal transcription and Tax transactivation in B cells.

\section{Conclusion}

Our study represents the largest study of the LTR genetic variability of BLV field isolates from Eastern part of Europe. The SNP screening showed variations modifying LTR regulatory sequences, as well as altering existing TFBS. Different sets of mutations for LTRs from different genotypes and subtypes suggests that multiple, geographically localized changes, may be involved in viral adaptation to recent selective pressures. These adaptations may underlie differential clinical outcomes of BLV infection, with potential implications for agricultural practice and economy [39-41].

\section{Additional file}

Additional file 1: Alignment of 60 representative full-length BLV LTR sequences. The labeled rectangles in the upper part of figure refer to the regulatory elements of LTR. Dots indicate identity with consensus sequence, generated based on the 81 sequences analyzed in this study. Abbreviations are included in the attached list of abbreviations. Classification of the sequences according to the genotypes/subtypes is shown in the left part of the figure. (ZIP $281 \mathrm{~kb}$ )

Additional file 2: LTR sequences from a total of 102 BLV field isolates used in this study, with GenBank accession numbers and geographic origin. (XLSX $14 \mathrm{~kb}$ )

\section{Abbreviations}

ACF: ATP-dependent chromatin-assembly factor; AFP1: Hepatoma nuclear factor that binds to the alpha-fetoprotein enhancer; AGID: Agar gel immunodiffusion; AP-1: Activator protein 1; ATF-1: Activating transcription factor-1; BLV: Bovine leukemia virus; bZip domain: Basic leucine zipper domain; CIIIB1: Nuclear factor; CRE: Cyclic AMP-responsive elements; CREB: Cyclic AMP response element binding protein; CREM-

tau2: Transcription factor CAMP-response element modulator protein; DAS: Downstream activator sequence; EBL: Enzootic bovine leukosis; ELISA: Enzyme-linked immunosorbent assay; ETS: E26 transformation-specific (ETS) transcription factors; GATA-1: Erythroid transcription factor;

GRE: Glucocorticoid response element; HBZ: HTLV-1 bZIP factor; HIV: Human immunodeficiency virus; HTLV: Human T-cell lymphotropic virus;

IRF: Interferon regulatory factor; LTR: Long terminal repeat; NFE2: TF

interacting with CREB-binding protein; NF-kB: Nuclear factor kB; PAS: Poly (A) signal sequence; PBLs: Peripheral blood leukocytes; Pit-1a: Growth hormone factor 1; PR: Progesterone; PU.1/Spi-B: Spi-B transcription factor; RARgamma2: Retinoic acid receptor gamma; SNP: Single nucleotide polymorphisms; Sp1: Specificity protein 1; TBP: TATA-binding protein; TFBS: Transcription factor binding site; TFIID: Transcription Factor II D; TfLF1: Liver-specific transcription factor; TMF: TATA element modulatory factor; 
TNFa: Tumor necrosis factor a; TRE: Tax-responsive element; USF: Upstream stimulatory factor; VNR : Non-regulatory sequences; VR: Regulatory sequences; XBP-3: X-box binding protein 1; KB: DNA binding site for nuclear factor $\mathrm{kB}$

\section{Acknowledgements}

The authors would like to acknowledge the funding of this work: this research was funded by KNOW (Leading National Research Centre) Scientific Consortium "Healthy Animal- Safe Food", decision of Ministry of Science and Higher Education of Poland No. 05-1/KNOW2/2015.

\section{Funding}

This work was supported by National Science Center under Grant "The effect of mutations in LTR region, tax gene and miRNA encoding region on replication of the Bovine Leukemia Virus in naturally infected cattle" No. UMO-2016/21/N/NZ6/02324. RND is funded by a Discovery grant from Natural Sciences and Engineering Research Council of Canada (NSERC \# RGPIN2016-05761)

\section{Availability of data and materials}

All data analyzed for the purposes of this manuscript are included in this article.

\section{Authors' contributions}

Drafted the concept and designed the study: AP; collected blood samples: AP; performed the experiments and analysed the data: AP; wrote the paper: $A P, J K$ and RND; revised the manuscript critically for important intellectual content: AP, JK, RND and MRŁ. All authors read and approved the final version of the manuscript.

\section{Ethics approval and consent to participate}

Not applicable.

\section{Consent for publication}

Not applicable.

\section{Competing interests}

The authors declare that they have no competing interests.

\section{Publisher's Note}

Springer Nature remains neutral with regard to jurisdictional claims in published maps and institutional affiliations.

\section{Author details}

${ }^{1}$ Department of Biochemistry, National Veterinary Research Institute, Puławy, Poland. ${ }^{2}$ Department of Biology, The University of Winnipeg, Winnipeg, MB, Canada. ${ }^{3}$ Department of Immunology, University of Manitoba, Winnipeg, MB, Canada.

\section{Received: 23 July 2018 Accepted: 25 September 2018}

Published online: 25 October 2018

\section{References}

1. Gillet N, Florins A, Boxus M, Burteau C, Nigro A, Vandermeers F, Balon H, Bouzar AB, Defoiche J, Burny A, et al. Mechanisms of leukemogenesis induced by bovine leukemia virus: prospects for novel anti-retroviral therapies in human. Retrovirology. 2007:4:18.

2. Derse D. Bovine leukemia virus transcription is controlled by a virusencoded trans-acting factor and by cis-acting response elements. J Virol. 1987;61(8):2462-71.

3. Katoh I, Kyushiki H, Sakamoto Y, Ikawa Y, Yoshinaka Y. Bovine leukemia virus matrix-associated protein MA(p15): further processing and formation of a specific complex with the dimer of the 5 '-terminal genomic RNA fragment. J Virol. 1991;65(12):6845-55.

4. Sagata N, Yasunaga T, Ogawa Y, Tsuzuku-Kawamura J, Ikawa Y. Bovine leukemia virus: unique structural features of its long terminal repeats and its evolutionary relationship to human T-cell leukemia virus. Proc Natl Acad Sci U S A. 1984;81(15):4741-5.

5. Rosen CA, Sodroski JG, Kettman R, Haseltine WA. Activation of enhancer sequences in type II human T-cell leukemia virus and bovine leukemia virus long terminal repeats by virus-associated trans-acting regulatory factors. J Virol. 1986;57(3):738-44.

6. Couez D, Deschamps J, Kettmann R, Stephens RM, Gilden RV, Burny A. Nucleotide sequence analysis of the long terminal repeat of integrated bovine leukemia provirus DNA and of adjacent viral and host sequences. J Virol. 1984;49(2):615-20.

7. Brooks PA, Nyborg JK, Cockerell GL. Identification of an NF-kappa B binding site in the bovine leukemia virus promoter. J Virol. 1995;69(10):6005-9.

8. Niermann GL, Buehring GC. Hormone regulation of bovine leukemia virus via the long terminal repeat. Virology. 1997;239(2):249-58.

9. Dekoninck A, Calomme C, Nizet S, de Launoit Y, Burny A, Ghysdael J, Van Lint C. Identification and characterization of a PU.1/Spi-B binding site in the bovine leukemia virus long terminal repeat. Oncogene. 2003;22(19):2882-96.

10. Merezak C, Pierreux C, Adam E, Lemaigre F, Rousseau GG, Calomme C, Van Lint C, Christophe D, Kerkhofs P, Burny A, et al. Suboptimal enhancer sequences are required for efficient bovine leukemia virus propagation in vivo: implications for viral latency. J Virol. 2001;75(15):6977-88.

11. Calomme C, Nguyen TL, de Launoit Y, Kiermer V, Droogmans L, Burny A, Van Lint C. Upstream stimulatory factors binding to an $\mathrm{E}$ box motif in the $\mathrm{R}$ region of the bovine leukemia virus long terminal repeat stimulates viral gene expression. J Biol Chem. 2002;277(11):8775-89.

12. Kiss-Toth $E$, Unk I. A downstream regulatory element activates the bovine leukemia virus promoter. Biochem Biophys Res Commun. 1994;202(3):1553-61.

13. Kiermer V, Van Lint C, Briclet D, Vanhulle C, Kettmann R, Verdin E, Burny A, Droogmans $L$. An interferon regulatory factor binding site in the $\mathrm{U} 5$ region of the bovine leukemia virus long terminal repeat stimulates taxindependent gene expression. J Virol. 1998;72(7):5526-34.

14. de Arellano ER, Alcami J, Lopez M, Soriano V, Holguin A. Drastic decrease of transcription activity due to hypermutated long terminal repeat (LTR) region in different HIV-1 subtypes and recombinants. Antivir Res. 2010;88(2):152-9.

15. Barros SC, Ramos F, Duarte M, Fagulha T, Cruz B, Fevereiro M. Genomic characterization of a slow/low maedi visna virus. Virus Genes. 2004;29(2): 199-210.

16. Angelopoulou K, Poutahidis T, Brellou GD, Greenland T, Vlemmas I. A deletion in the $R$ region of long terminal repeats in small ruminant lentiviruses is associated with decreased pathology in the lung. Vet J. 2008; 175(3):346-55.

17. Oskarsson T, Hreggvidsdottir HS, Agnarsdottir G, Matthiasdottir S, Ogmundsdottir MH, Jonsson SR, Georgsson G, Ingvarsson S, Andresson OS, Andresdottir $\mathrm{V}$. Duplicated sequence motif in the long terminal repeat of maedi-visna virus extends cell tropism and is associated with neurovirulence. J Virol. 2007;81(8):4052-7.

18. Neto WK, Da-Costa AC, de Oliveira AC, Martinez VP, Nukui Y, Sabino EC, Sanabani SS. Correlation between LTR point mutations and proviral load levels among human T cell lymphotropic virus type 1 (HTLV-1) asymptomatic carriers. Virol J. 2011;8:535.

19. Polat M, Takeshima SN, Hosomichi K, Kim J, Miyasaka T, Yamada K, Arainga M, Murakami T, Matsumoto Y, de la Barra DV, et al. A new genotype of bovine leukemia virus in South America identified by NGS-based whole genome sequencing and molecular evolutionary genetic analysis. Retrovirology. 2016;13:4

20. Rola-Luszczak M, Pluta A, Olech M, Donnik I, Petropavlovskiy M, Gerilovych A, Vinogradova I, Choudhury B, Kuzmak J. The molecular characterization of bovine leukaemia virus isolates from Eastern Europe and Siberia and its impact on phylogeny. PLoS One. 2013:8(3):e58705.

21. Rodriguez SM, Golemba MD, Campos RH, Trono K, Jones LR. Bovine leukemia virus can be classified into seven genotypes: evidence for the existence of two novel clades. J Gen Virol. 2009;90(Pt 11):2788-97.

22. Zhao X, Jimenez C, Sentsui $H$, Buehring GC. Sequence polymorphisms in the long terminal repeat of bovine leukemia virus: evidence for selection pressures in regulatory sequences. Virus Res. 2007;124(1-2):113-24.

23. Hirsch C, Camargos MF, Barbosa-Stancioli EF, Fonseca Junior AA, Rajao DS, Heinemann MB, Reis JK, Leite RC. Genetic variability and phylogeny of the $5^{\prime}$ long terminal repeat from Brazilian bovine leukemia virus. Genet Mol Res. 2015;14(4):14530-8.

24. Moratorio G, Fischer S, Bianchi S, Tome L, Rama G, Obal G, Carrion F, Pritsch $\mathrm{O}, \mathrm{Cristina}$ J. A detailed molecular analysis of complete bovine leukemia virus genomes isolated from B-cell lymphosarcomas. Vet Res. 2013;44:19.

25. Juliarena MA, Lendez PA, Gutierrez SE, Forletti A, Rensetti DE, Ceriani MC. Partial molecular characterization of different proviral strains of bovine leukemia virus. Arch Virol. 2013;158(1):63-70. 
26. Rodriguez SM, Florins A, Gillet N, de Brogniez A, Sanchez-Alcaraz MT, Boxus M, Boulanger F, Gutierrez G, Trono K, Alvarez I, et al. Preventive and therapeutic strategies for bovine leukemia virus: lessons for HTLV. Viruses. 2011:3(7):1210-48.

27. Kearse M, Moir R, Wilson A, Stones-Havas S, Cheung M, Sturrock S, Buxton S, Cooper A, Markowitz S, Duran C, et al. Geneious basic: an integrated and extendable desktop software platform for the organization and analysis of sequence data. Bioinformatics. 2012;28(12):1647-9.

28. Hahn MW, Rockman MV, Soranzo N, Goldstein DB, Wray GA. Population genetic and phylogenetic evidence for positive selection on regulatory mutations at the factor VII locus in humans. Genetics. 2004;167(2):867-77.

29. Zhao X, McGirr KM, Buehring GC. Potential evolutionary influences on overlapping reading frames in the bovine leukemia virus PXBL region. Genomics. 2007;89(4):502-11.

30. Kimura M. Preponderance of synonymous changes as evidence for the neutral theory of molecular evolution. Nature. 1977;267(5608):275-6.

31. Calomme C, Dekoninck A, Nizet S, Adam E, Nguyen TL, Van Den Broeke A, Willems L, Kettmann R, Burny A, Van Lint C. Overlapping CRE and E box motifs in the enhancer sequences of the bovine leukemia virus $5^{\prime}$ long terminal repeat are critical for basal and acetylation-dependent transcriptional activity of the viral promoter: implications for viral latency. $\rfloor$ Virol. 2004;78(24):13848-64.

32. Xiao J, Buehring GC. In vivo protein binding and functional analysis of cisacting elements in the U3 region of the bovine leukemia virus long terminal repeat. J Virol. 1998;72(7):5994-6003.

33. Kashanchi F, Duvall JF, Lindholm PF, Radonovich MF, Brady JN. Sequences downstream of the RNA initiation site regulate human T-cell lymphotropic virus type I basal gene expression. J Virol. 1993;67(5):2894-902.

34. Asin SN, Heimberg AM, Eszterhas SK, Rollenhagen C, Howell AL. Estradiol and progesterone regulate HIV type 1 replication in peripheral blood cells. AIDS Res Hum Retrovir. 2008;24(5):701-16.

35. Ono M, Kawakami M, Ushikubo H. Stimulation of expression of the human endogenous retrovirus genome by female steroid hormones in human breast cancer cell line T47D. J Virol. 1987;61(6):2059-62.

36. Jeeninga RE, Hoogenkamp M, Armand-Ugon M, de Baar M, Verhoef K Berkhout B. Functional differences between the long terminal repeat transcriptional promoters of human immunodeficiency virus type 1 subtypes a through G. J Virol. 2000;74(8):3740-51.

37. Arainga M, Takeda E, Aida Y. Identification of bovine leukemia virus tax function associated with host cell transcription, signaling, stress response and immune response pathway by microarray-based gene expression analysis. BMC Genomics. 2012;13:121.

38. Wagner EF, Eferl R. Fos/AP-1 proteins in bone and the immune system. Immunol Rev. 2005:208:126-40.

39. Murakami H, Uchiyama J, Suzuki C, Nikaido S, Shibuya K, Sato R, Maeda Y, Tomioka M, Takeshima SN, Kato H, et al. Variations in the viral genome and biological properties of bovine leukemia virus wild-type strains. Virus Res. 2018:253:103-11

40. John EE, Nekouei O, McClure JT, Cameron M, Keefe G, Stryhn H. Investigation of within- and between-herd variability of bovine leukaemia virus bulk tank milk antibody levels over different sampling intervals in the Canadian Maritimes. Prev Vet Med. 2018;154:90-4.

41. Nekouei O, VanLeeuwen J, Stryhn H, Kelton D, Keefe G. Lifetime effects of infection with bovine leukemia virus on longevity and milk production of dairy cows. Prev Vet Med. 2016;133:1-9.

42. Derse D, Diniak AJ, Casey JW, Deininger PL. Nucleotide sequence and structure of integrated bovine leukemia virus long terminal repeats. Virology. 1985;141(1):162-6

43. Murakami H, Uchiyama J, Nikaido S, Sato R, Sakaguchi M, Tsukamoto K. Inefficient viral replication of bovine leukemia virus induced by spontaneous deletion mutation in the G4 gene. J Gen Virol. 2016;97(10):2753-62.

44. Dube S, Dolcini G, Abbott L, Mehta S, Dube D, Gutierrez S, Ceriani C, Esteban E, Ferrer J, Poiesz B. The complete genomic sequence of a BLV strain from a Holstein cow from Argentina. Virology. 2000;277(2):379-86.

45. Polat M, Moe HH, Shimogiri T, Moe KK, Takeshima SN, Aida Y. The molecular epidemiological study of bovine leukemia virus infection in Myanmar cattle. Arch Virol. 2017;162(2):425-37.

\section{Ready to submit your research? Choose BMC and benefit from:}

- fast, convenient online submission

- thorough peer review by experienced researchers in your field

- rapid publication on acceptance

- support for research data, including large and complex data types

- gold Open Access which fosters wider collaboration and increased citations

- maximum visibility for your research: over $100 \mathrm{M}$ website views per year

At BMC, research is always in progress.

Learn more biomedcentral.com/submissions 